\title{
Situación y perspectivas de la Sociedad Cooperativa Europea ${ }^{1}$
}

\author{
Carlos Vargas Vasserot \\ Catedrático Acrd. de Derecho Mercantil \\ Universidad de Almería
}

Sumario: I. Introducción al Derecho de sociedades de la Unión Europea. II. La creación de entidades supranacionales en Europa. III. Los objetivos perseguidos con la aprobación del Estatuto de la Sociedad Cooperativa Europea. IV. Estructura del Reglamento que aprueba el Estatuto de la Sociedad Cooperativa Europea y breve referencia al contenido de la Directiva respeto a la implicación de los trabajadores. V. Naturaleza y características de la Sociedad Cooperativa Europea. VI. El complejo sistema de fuentes del Estatuto de la Sociedad Cooperativa Europea. VII. Situación y perspectivas. VIII. Bibliografía.

Resumen: El Estatuto de la Sociedad Cooperativa Europea (SCE) está integrado por dos disposiciones complementarias. De un lado, el Reglamento CE 1435/2003 «relativo al Estatuto de la Sociedad Cooperativa Europea» (RSCE) y, de otro, la Directiva 2003/72/CE del Consejo «por la que se completa el Estatuto de la Sociedad Cooperativa Europea en lo que respecta a al implicación de los trabajadores». Mediante esta forma jurídica supranacional se pretendía dotar a las cooperativas europeas de un instrumento que les permitiera desarrollar actividades transfronterizas de carácter internacional. Pero después de casi diez años de su puesta en marcha, la figura supranacional no ha funcionado. Hasta 2012 sólo se habían constituido en Europa veinticuatro sociedades cooperativas europeas, con un número de trabajadores inferior a cincuenta, siendo además llamativo el escaso número de las creadas en países con un movimiento cooperativo tan activo, como son Francia, España o Alemania. Consciente de esta realidad, la Comisión europea evaluó a través de una consulta pública los motivos de la escasa adhesión del cooperativismo europeo al esta-

1 Trabajo realizado en el marco del Proyecto de Investigación de Excelencia de la Junta de Andalucía P12-SEJ-2555, «Retos y oportunidades en la concentración e integración de las empresas agroalimentarias», del que el profesor Vargas Vasserot es el Investigador Principal, y que tiene como base la ponencia presentada, como miembro de la AIDC, a la XVIII Conferencia Regional ACI Américas, celebrada en Guarujá (Sao Paulo) en octubre de 2013. 
tuto de la SCE y en febrero de 2012 se publicó un Informe sobre la aplicación del RSCE, que finalizaba con la necesaria revisión de su contenido. El presente estudio analizará el origen y las razones de la creación de las entidades supranacionales en el Derecho de sociedades europeo, para posteriormente analizar el contenido del RSCE, su complejo sistema de fuentes y las razones del fracaso de la figura, exponiendo las diversas medidas de reforma propuestas por la Comisión Europea, con objeto de hacer el tipo legal más atractivo para el movimiento cooperativo europeo.

Palabras clave: Sociedad Cooperativa Europea; integración de cooperativas; entidades supranacionales; internacionalización; Derecho de sociedades europeo; cooperativas; concentración de empresas.

Abstract: The Statute for a European Cooperative Society (SCE) comprises two complementary provisions. Council Regulation EC no. 1435/2003 "on the statute for a European Cooperative Society» and Council Directive 2003/72/EC «supplementing the Statute for a European Cooperative Society with regard to the involvement of employees". This supranational legal arrangement aims to endow European cooperatives with an instrument that would enable them to carry out international cross-border activities. However, nearly ten years following its implementation, the supranational scheme has not worked. Only twenty four European cooperative societies with fewer than fifty workers had been set up in Europe by 2012. It is striking that so few were created in countries such as France, Spain or Germany with such an active cooperative movement. Aware of this reality, the European Commission held a public consultation to examine the reasons for the poor adhesion of European cooperativism to the SCE Statute. In February 2012, a report on implementation of the ECS Regulation was published, marking finalisation of the necessary revision of its contents. This study analyses the origin and reasons for creating supranational entities in European Company Law and goes on to examine the content of the ECS Regulation, its complex system of sources and the reasons it failed. The different reform measures proposed by the European Commission to make the legal means more attractive to the European cooperative movement are also explained.

Key words: European Cooperative Society; integration of cooperatives; supranational entities; internationalisation; European Company Law; cooperatives; concentration of companies 


\section{Introducción al Derecho de sociedades de la Unión Europea}

En Europa el fenómeno cooperativo está bien asentado. Como señala el reciente Informe sobre «La contribución de las cooperativas a la salida de la crisis», aprobado por el Parlamento Europeo en junio de 2013, en el viejo Continente existen alrededor de 160.000 empresas cooperativas, que asocian a 123 millones de socios, que proporcionan empleo a 5,4 millones de personas y que contribuyen aproximadamente en un 5\% de media, al PIB de los estados miembros. El Informe recuerda la necesidad de que la Unión Europea reconozca y trate del mismo modo, a través de disposiciones legislativas, las distintas formas de emprendimientos, de manera que se garantice el respeto del principio de libertada de actuación empresarial, cualquiera que sea el estatuto de la empresa. De este modo, y aunque no existe una gran uniformidad entre los diversos ordenamientos europeos a la hora de regular el Derecho cooperativo, desde las mismas instituciones europeas se aboga por la homogeneización normativa y la igualdad de trato respecto al resto de empresas.

En Europa conviven, al menos, dos tradiciones jurídicas diferentes en la configuración del fenómeno cooperativo: la economicista o funcional, que persigue básicamente la promoción de los intereses económicos de sus socios, que se da en el norte de Europa y Gran Bretaña; y la latina, más social y fiel a los principios cooperativos de la $\mathrm{ACl}$, que se sigue por ejemplo en Italia, Francia, España y Portugal. Aunque hay que reconocer que en las últimas décadas se ha producido un acercamiento de los ordenamientos latinos (sobre todo por parte de algunas leyes cooperativas españolas) a la concepción economicista del cooperativismo, no se puede obviar las tremendas diferencias que aún existe entre los distintos ordenamientos de la Unión Europea. Esto es importante advertirlo porque, como veremos, en la creación de la Sociedad Cooperativa Europea (SCE, de su nombre en latín Societas Cooperativa Europaea), figura de la que trata esta aportación, el legislador europeo ha partido de un modelo economicista, aunque tan permeable por las normas nacionales de los Estados donde se domicilie la sociedad y por los propios estatutos sociales que el resultado ha sido un híbrido que no ha contentado a nadie.

Pero vayamos por partes, empezando con una breve introducción al Derecho de sociedades europeo que sirva para conocer las razones de la creación de las diversos entes jurídico supranacionales existentes en Europa.

La elaboración del Derecho comunitario, en general, se asienta en una serie de principios contenidos en el Tratado de Funcionamiento 
de la Unión Europea (TFUE) que establecen las competencias de la Unión Europea en la materia (principio de atribución, de subsidiariedad y de proporcionalidad). En el Derecho de sociedades, en particular, el principio fundamental es el de libertad de establecimiento, consagrado en el capítulo 2 (arts. 49 y ss.), Título IV (Libre circulación de personas, servicios y capitales) de la tercera parte del TFUE, dedicada a las políticas de la Comunidad. Para las personas jurídicas este derecho de establecimiento, que se recoge en el artículo 49.3 TFUE (antiguo artículo 43 TCE), significa la posibilidad de transferir de un Estado miembro a otro el centro principal de actividades y el derecho a obtener un tratamiento nacional —es decir, análogo al de los nacionales del país de establecimiento- en todo lo concerniente a la constitución y gestión de toda clase de empresas y especialmente de sociedades.

Pero la tendencia inicial del legislador comunitario fue ir más allá del principio de no discriminación y paulatinamente desde finales de la década de los años sesenta se fue produciendo una gradual aproximación jurídica de las legislaciones nacionales a través de la llamada armonización del Derecho de sociedades comunitario para facilitar a la progresiva internacionalización de las relaciones económicas dentro de la Unión Europea. Esta armonización societaria se ha ido construyendo esencialmente a través de la promulgación de directivas con objeto de alcanzar la comentada libertad de establecimiento, algo que permitía expresamente el Tratado de la Comunidad Europea (art. 50.2 TFUE, antiguo art. 44.2 TCE). Cabe recordar que a diferencia de los reglamentos, las directivas no son de directa aplicación, sino que contienen unos mínimos de necesaria su trasposición al Derecho interno, lo que permite una mayor adecuación de la normativa europea a las peculiaridades jurídicas de cada país, pero conlleva un necesario proceso de incorporación que puede retrasar su entrada en vigor y significar ciertas diferencias de contenido entre la regulación de unos Estados y otros.

Hasta ahora se han promulgado once directivas en la materia (que ninguna afecta directamente a las cooperativas y muy pocas a las sociedades de responsabilidad limitada), y aún hoy el núcleo del Derecho de sociedades comunitario lo constituyen estas directivas de armonización que pasamos simplemente a enumerar: Primera Directiva del Consejo (68/151/CEE), que en concreto trata «la publicidad de la sociedad, validez de los actos realizados en nombre de la sociedad y nulidad de sociedades»; Segunda Directiva del Consejo (77/91/ CEE) «para proteger los intereses de socios y terceros, en lo relativo a la constitución de la sociedad anónima, así como al mantenimiento 
y modificación de su capital»; Tercera Directiva del Consejo (78/855/ CEE) «relativa a las fusiones de las sociedades anónimas»; Cuarta Directiva del Consejo (78/660/CEE) «relativa a las cuentas anuales de determinadas formas de sociedad»; Sexta Directiva del Consejo (82/891/CEE) «referente a la escisión de sociedades anónimas»; Séptima Directiva del Consejo (83/349/CEE) «relativa a las cuentas consolidadas»; Octava Directiva del Consejo (84/253/CEE) «relativas a la autorización de las personas encargadas del control legal de documentos contables»; Décima Directiva del Parlamento y el Consejo (2005/56/CE) «relativa a fusiones transfronterizas de sociedades de capital»; Undécima Directiva del Consejo (89/666/CEE), «relativa a la publicidad de las sucursales constituidas en un Estado miembro por determinadas formas de sociedades sometidas al Derecho de otro Estado»; Duodécima Directiva del Consejo (89/667/CEE), «relativa a la sociedad de responsabilidad limitada de socio único»; y Decimotercera Directiva del Parlamento y el Consejo (2004/25/CE) «relativa a la oferta pública de adquisiciones».

Como se aprecia, la numeración de las directivas no es correlativa ni responde a un riguroso orden cronológico, ya que el ordinal de cada directiva corresponde al momento en el que se realizó la propuesta por parte de la Comisión, y a veces el retraso en la tramitación de una directiva ha hecho que se publique antes otra iniciada posteriormente $y$, en otras ocasiones, una propuesta no ha llegado a convertirse en directiva (por ejemplo, la propuesta de Novena Directiva sobre Derecho de grupos). A partir de los años noventa se produjo una grave crisis de este mecanismo de acercamiento normativo, provocada especialmente por la resistencia de los Estados miembros a introducir elementos ajenos a su tradición jurídica y por la presencia de nuevos principios e ideas sobre el juego de la autonomía de la voluntad y de la competencia entre distintas legislaciones. Todo esto obligó al legislador Europeo a cambiar su estrategia en el Derecho comunitario hacia un mayor respeto del ámbito de competencia de los legisladores nacionales y una mayor desregulación legislativa con más libertad contractual para los actores económicos, con la consecuente desaceleración del proceso de armonización en materia de sociedades. El desbloqueo a la situación de parálisis normativa llegó con el compromiso político alcanzado en el Consejo Europeo de Niza (diciembre de 2000) de impulsar la Propuesta de Directiva que completara el Estatuto de la Sociedad Anónima Europea respecto a la implicación de los trabajadores, abriéndose así el camino para la aprobación del Reglamento del Estatuto de la Sociedad Anónima Europa y su Directiva complementaria en el año 2001. 


\section{La creación de entidades supranacionales en Europa}

En el Tratado de Funcionamiento de la Unión Europea en materia de competencias existe la denominada cláusula de cierre del sistema comunitario (artículo 352 TFUE; antiguo artículo 308 TCE), también denominada cláusula general de competencia sobre competencias, por la que con el objeto de suplir la inexistencia de poderes de acción para lograr alguno de los objetivos fijados en los Tratados, el Consejo podía aprobar las disposiciones que estimase necesarias, como ocurrió elaborar el Reglamento 2137/85/CEE relativo a la constitución de una Agrupación Europea de Interés Económico (AEIE). A este mismo precepto se acudió para la creación de la Sociedad Anónima Europea (se cita SE, del latín Societas Europeae), pero ante la imposibilidad de llegar a un acuerdo sobre determinados aspectos de su régimen, se acudió a una solución de urgencia y muy novedosa: la doble regulación (Reglamento y Directiva) para superar los bloqueos políticos por las diferencias en cuanto a la estructura societaria (estructura monista/ dualistas) y la participación de los trabajadores de los distintos países miembro (cogestión de los trabajadores). Finalmente el Consejo Europeo aprobó el Reglamento 2157/2001 relativo al Estatuto de las Sociedad Anónima Europea y la Directiva 2001/86/CE por la que se completa el Estatuto de las Sociedad Anónima Europea en lo que respecta a la implicación de los trabajadores. Y esta misma técnica fue usada para aprobar el Reglamento 1435/2003 relativo al Estatuto de la Sociedad Cooperativa Europea y la Directiva 2003/72/CE por la que se completa el Estatuto de la Sociedad Cooperativa Europea en lo que respecta a al implicación de los trabajadores.

La concepción final de la SE, que es en la que ahora nos centramos, evolucionó mucho desde el proyecto de Estatutos elaborado por el Prof. Sanders en 1966, ya que inicialmente se concibió como una SA exclusivamente europea, en las que todos sus aspectos societarios eran regulados por su Estatuto legal. Finalmente se redujeron mucho el número de preceptos del Estatuto, se cedió gran parte de su regulación a los derechos internos y, en consecuencia, se terminó por crear un tipo híbrido comunitario-nacional. A pesar del tiempo invertido (más de treinta años), el fruto no fue del agrado de los operadores económicos, que prefieren ejercer el principio de libertad de establecimientos o llevar a cabo fusiones transfronterizas intracomunitarias, cuyo régimen ha sido simplificado y abaratado tras la publicación de la Décima Directiva (2005/56/CE) y de varias Directiva posteriores que la han modificado (Directiva 2009/109/CE y Directiva 2012/17/UE), que acudir a un tipo social novedoso, rígido y con un 
complicado sistema de fuentes, que suponen importantes costes de constitución (la media se tasa cercana al millón de dólares) y administrativos.

Además, hay que tener en cuenta que la libertad de establecimiento en Europa ha sido jurisprudencialmente muy reforzada, ya que el TJCE ha dictado varias sentencias sobre la materia [casos Centros (C-212/97), Inspire Art (C-167/01), Überseering (C-208/00) y Sevic (C-411/2003)], que reconocen el Derecho de las sociedades a abrir una sucursal inmediatamente después de haberse constituido para realizar su actividad empresarial, incluso de manera principal, en un Estado miembro de la Unión Europea distinto al suyo y la obligación de dicho Estado de tratarlo igual que a una sociedad nacional. De este modo, las sociedades europeas, del tipo que sean, independientemente del cuál sea la nacionalidad o el origen de los socios, pueden elegir constituirse en el Estado miembro de la Unión Europea que deseen (o que tenga unas condiciones de constitución más favorables) y abrir una o varias sucursales en los Estados miembros que les interese explotar su negocio. Con una libertad de establecimiento de personas jurídicas tan asentada en el Derecho comunitario, no existen verdaderos incentivos para que los operadores económicos constituyan entidades supranacionales

Hasta ahora las figuras supranacionales creadas no han funcionado, con cifras irrisorias de constitución. En 2010 había aproximadamente quinientas SE constituidas, la mayoría en Alemania para aprovecharse de la libertad de traslado de domicilio social o eludir las obligaciones de cogestión típicas de su ordenamiento, y sobre todo, en Eslovaquia, que se constituyen para transmitirlas después a terceros. A pesar de que las críticas han sido casi unánimes por parte de la doctrina (se habla de bodrio, aborto, esperpento), el legislador europeo no ha abandonado este mecanismo de integración y concentración de fenómenos asociativos. Así, en 2008 se presentó una Propuesta de Reglamento del Estatuto de la a Sociedad Privada Europea (SPE), con el que se pretende crear una forma simplificada de sociedad de responsabilidad limitada europea de ámbito supranacional que favorezca el establecimiento y funcionamiento de las pequeñas y medianas empresas (PYME). Más recientemente, en 2012, se ha aprobado la Propuesta de Reglamento del Estatuto de la Fundación Europea (FE), con la que se quiere crear una nueva forma jurídica europea cuyo propósito es facilitar la constitución de fundaciones y su funcionamiento en el mercado único. Más complicado parece la puesta en marcha de la Asociación Europea $(A E)$ y de la Mutua Europea (ME), cuyos proyectos se puesta en marcha están hoy día paralizados. 


\section{Los objetivos perseguidos con la aprobación del Estatuto de la Sociedad Cooperativa Europea}

El Estatuto de la Sociedad Cooperativa Europea (SCE) está integrado por dos disposiciones complementarias. De un lado, el Reglamento CE 1435/2003 del Consejo, de 22 de julio de 2003, «relativo al Estatuto de la Sociedad Cooperativa Europea» (RSCE) y, de otro, la Directiva 2003/72/CE del Consejo, de la misma fecha, «por la que se completa el Estatuto de la Sociedad Cooperativa Europea en lo que respecta a al implicación de los trabajadores».

El objetivo de las formas jurídicas supranacionales comunitarias es generar instrumentos societarios jurídicos que den respuesta, de una manera eficaz (reducción de costes y simplificación de procesos) a los procesos concentración empresarial entre entidades que actúan en distintos Estados miembros. Se intentan ofrecer así a las empresas europeas vías adecuadas para realizar operaciones de cooperación y concentración intracomunitaria puesto que la necesidad de recurrir a un determinado Derecho nacional aplicable a sociedad resultante de la fusión, para las filiales o para las sociedades de control, origina obstáculos y costes diversos que se pretende evitar con estos tipos sociales transnacionales. De otro lado, se dice que los empresarios pueden utilizar una forma jurídica europea, cuyo régimen, en teoría, es más conocido que los tipos sociales nacionales, con lo que se puede penetrar más fácilmente en los mercados de otros Estados miembros, destacando además la afiliación europea de la empresa que le puede dar imagen de confianza y fortaleza (marca Europa) que facilite la entrada en determinados mercados nacionales.

En el caso concreto del Estatuto de la SCE, se pretende dotar a las cooperativas de un instrumento en el ámbito del Derecho de sociedades que permita mejorar la situación económica y social en el conjunto de la Unión Europea, reduciendo obstáculos del mercado interior y potenciando el desarrollo entre regiones y Estados miembros a través de la fórmula jurídica cooperativa sin necesidad de crear otras sociedades mercantiles para desarrollar en una sola estructura jurídica cooperativa actividades transfronterizas. De este modo, el principal motivo para la aprobación del RSCE fue dotar a cooperativas de un instrumento normativo específico para desarrollar actividades transfronterizas y satisfacer así sus necesidades de actuación supranacional, puesto que las otras figuras societarias de origen comunitario existentes no era aptas para lograr los fines económicos y sociales de estas peculiares formas de empresas.

Aunque las Agrupaciones de Interés Económico facilitan y fomentan las actividades económicas comunes de sus miembros, sólo puede 
tener un carácter auxiliar a la actividad principal de sus socios, con lo que no se logra la pretendida integración plena de las economías de los miembros que pretende el tipo cooperativo. Aparte, la típica responsabilidad ilimitada de los socios de la AEIE constituye un claro desincentivo a la constitución de entidades de este tipo para desarrollar actividades mutualistas. En cuanto a la SE, si bien se puede configurar con rasgos mutualistas, los principios que rigen esta forma societaria capitalista no se adapta a las características específicas de las cooperativas, que en gran medida deriva del necesario respeto de los principios cooperativos.

La otra razón apuntada para la elaboración del Estatuto de la SCE era la exigencia de tratar a las cooperativas en plano de igualdad respecto al resto de las sociedades de capital. Como reconoce el RSCE en su considerando sexto, que declara que la UE, en su afán de respetar la igualdad de condiciones de la competencia y de contribuir a su desarrollo económico, debe dotar a las cooperativas de instrumentos jurídicos adecuados que permitan facilitar el desarrollo de sus actividades transfronterizas. O dicho de otra manera, si para las sociedades anónimas europeas se creó la SE, se debía hacer lo mismo para las cooperativas europeas con la SCE. El error, en mi opinión, es que no se esperó a ver cómo funcionaba el tipo supranacional creado para las anónimas, por lo que se repitieron los mismos errores a la hora de elaborar el Estatuto de la SCE que el de la SE. Y, cómo se preguntaba la doctrina especializada que barruntaba el fracaso de la institución, la cuestión era dilucidar si el Estatutos de la SCE sería sólo una herramienta simbólica o si realmente iba a servir para promover la reorganización e integración de las cooperativas existentes a escala comunitaria. Los hechos han demostrado que, hasta ahora, ha quedado en una mera herramienta simbólica, lo que es poco en comparación con los recursos y esfuerzos consumidos y las esperanzas depositadas por parte del movimiento cooperativo europeo.

\section{Estructura del Reglamento que aprueba el Estatuto de la Sociedad Cooperativa Europea y breve referencia al contenido de la Directiva respeto a la implicación de los trabajadores}

El Reglamento que aprueba el Estatuto de la Sociedad Cooperativa Europea se compone de nueve capítulos de contenido y extensión muy dispar. Los capítulos I, II y III, consumen más de la mitad de todo su articulado y son, sin duda, los más importantes. A partir de ahí el resto de los capítulos tienen de uno a tres artículos y tratan cuestiones mu- 
cho más específicas que bien se podían haber englobado en un capítulo final y único.

El Capítulo I, con el título de «Disposiciones generales» (arts. 1-16), aborda temas muy diversos e importantes, como el de la naturaleza de la SCE, su constitución, capital social y capital mínimo, contenido de los estatutos sociales, el domicilio social de la SCE y la intrincada posibilidad de su traslado, el sistema de fuentes, el principio de no discriminación de trato por los Estados en que se constituyan, la publicidad de la SCE y la adquisición y pérdida de la condición de socio y los derechos pecuniarios asociados a la baja.

El Capítulo II se intitula "Constitución» (arts. 17-35), que es como se denomina el artículo 2 del Capítulo I, trasluciéndose una vez más la falta de sistemática que impera en todo el RSCE. Dicho capítulo, parte de unas disposiciones generales, para pasar posteriormente a detallar las distintas vías por las que se puede constituir una SCE. A saber, constitución mediante fusión por absorción o por constitución de una nueva entidad, y transformación de una cooperativa existente en SCE.

El Capítulo III trata de un tema crucial, como es de la «Estructura de la SCE» (arts. 36-63), distinguiendo entre el sistema dual (conformado por una asamblea general, un órgano de control y un órgano de dirección) y el sistema monista (conformado por la asamblea general y un órgano de administración), regulando las competencias de los distintos órganos de la SCE, de su convocatoria y el régimen de adopción de acuerdos y ejercicio del derecho de voto.

El Capítulo IV regula la «Emisión de títulos con privilegios específicos» (art. 64), el Capítulo V la "Aplicación de los resultados» (arts. 65-67), el Capítulo VI trata de las «Cuentas anuales y cuentas consolidadas» (arts. 68-71) y el Capítulo VII aborda la «Disolución, liquidación, insolvencia y suspensión de pagos» de la SCE (arts. 72-75). El Capítulo VIII sobre «Unión Económica y Monetaria» (art. 77) se refiere al régimen de la SCE en los Estados que no les sea aplicable la tercera fase de la Unión Europea. El Capítulo IX contiene las «Disposiciones finales» (arts. 78-80) que, entre otros aspectos, señala la entrada en vigor del RSCE a los tres días de su publicación en el DOCE (agosto de 2003) y un retraso en su aplicación del Reglamento hasta agosto de 2006, que era cuando se tenía que haber traspuesto e todos los países la Directiva sobre la implicación de los trabajadores.

Como ha puesto de manifiesto la doctrina, estamos ante un texto legal mediocre, por su falta de sistemática y de rigor terminológico y técnico-jurídico y por numerosas remisiones a legislación de las sociedades anónimas y de cooperativas del Estado miembro del domicilio social de la SCE y a los estatutos de ésta, que dan como resultado una 
figura muy indefinida, que parece un híbrido entre un ente supranacional, una cooperativa nacional y una sociedad capitalista.

Por poner algún ejemplo de la falta de cuidado terminológico del que hablamos, el artículo 75 RSCE que regula la adjudicación del activo en caso de disolución de la SCE, establece que éste se hará con arreglo "al principio de adjudicación desinteresada», concepto que, al menos a los juristas españoles, nos resulta extraño, y que se debe entender que el activo social se adjudica a otra entidad que persiga objetivos similares o fines de interés general. Pero la palma, en lenguaje críptico, en mi opinión, se la lleva el artículo 79, b) sobre el contenido del Informe que debe presentar la Comisión Europea sobre la aplicación y posible revisión del RSCE a los cinco años de su «entrada en vigor» (debería decir de la aplicación del Reglamento) que me parece un auténtico galimatías y que trascribo a continuación: «En particular, el informe analizará la conveniencia de permitir disposiciones en los estatutos de la SCE adoptadas por un Estado miembro en ejecución de las autorizaciones conferidas a los Estados miembros por el presente Reglamento o leyes adoptadas para velar por la efectiva aplicación del mismo respecto de la SCE, que se aparten de dichas leyes o las complementen, aun en los casos en que tales disposiciones no se autorizarían en los estatutos de una cooperativa con domicilio social en el Estado miembro».

Por otra parte, está la Directiva 2003/72/CE del Consejo, de la misma fecha que el RSCE, «por la que se completa el Estatuto de la Sociedad Cooperativa Europea en lo que respecta a al implicación de los trabajadores». La Directiva, a diferencia del Reglamento, exige un ejercicio de transposición a los Estados miembros por la correspondiente ley nacional, cuyo plazo en agosto de 2006. En España, por ejemplo, dicha Directiva (y la similar sobre la SE) se traspuso a través de la Ley 31/2006, sobre implicación de los trabajadores en las sociedades anónimas y cooperativas europeas.

Respecto al contenido de la Directiva, ésta prevé el procedimiento de negociación para garantizar que la constitución de una SCE no suponga la desaparición ni la reducción de las prácticas existentes de implicación de los trabajadores en las entidades que participen en la creación de la SCE, tan típicas en el Derecho alemán con su sistema de cogestión (en el que se le otorga hasta la mitad de los puestos del Consejo de Vigilancia a los representantes sindicales) y tan desconocidas en otros países de la UE. Fue precisamente la negativa de los diferentes Estados miembros en ceder en este ámbito (Alemania a favor de imponer el sistema de cogestión y los países latinos a favor de liberalizar esta cuestión), la que obligó a la imaginativa doble regulación de la SE y de la SCE en un Reglamento y una Directiva. 
Según la Directiva 2003/72/CE, cuando los administradores de las entidades participantes establezcan el proyecto de constitución de una SCE, deben iniciar lo antes posible las gestiones necesarias para entablar negociaciones con los representantes sindicales sobre las disposiciones relativas a la implicación de los trabajadores en la SCE. A tal fin, se debe constituir una comisión negociadora representativa de los trabajadores de las entidades jurídicas participantes correspondiéndole a esta comisión y a los órganos competentes de las entidades participes la fijación mediante acuerdo escrito, de cual va a ser la implicación de los trabajadores en la SCE a constituir.

\section{Naturaleza y características de la Sociedad Cooperativa Europea}

El artículo 1 del RSCE, con el título de «naturaleza de la SCE», contiene disposiciones de carácter muy diverso con las que se pretende conformar los elementos esenciales de esta figura societaria supranacional. De dicho precepto se deduce una concepción de la SCE como una sociedad con personalidad jurídica, de capital variable divido en participaciones y con un número de socios también variable, que, en principio, tienen responsabilidad limitada y cuyo objeto principal es la satisfacción de las necesidades y el fomento de las actividades económicas y sociales de los socios. Pero como es fácil deducir, esta definición es incompleta puesto que omite muchas de las notas básicas de las sociedades cooperativas y, sobre todo, falta una referencia al necesario elemento transnacional de la entidad.

En cuanto a la omisión de algunas características típicas de las cooperativas, es decir de los principios cooperativos, en este artículo y en casi todo el RSCE, se debe atribuir a la influencia del Derecho de cooperativas alemán en su elaboración, que se caracteriza por un tradicional alejamiento con los principios de la $\mathrm{ACl}$. A pesar de ello, cabe reseñar que en los considerandos 7 y 8 se hace referencia a que las cooperativas se rigen por principios específicos, distintos de los de otros agentes económicos, y menciona, en particular, el de la estructura y gestión democrática, el de distribución equitativa del resultado y el de la primacía de las personas sobre el capital. Por su parte, el considerando 10 del Reglamento reconoce que la SCE debe respetar una serie de principios (beneficio mutuo, reparto control, beneficios en función de la participación...). Pero después, en el articulado del RSCE, todos estos principios no se recogen de manera explícita y sólo se puede reconocer el de ingreso libre y voluntario (1. ${ }^{\circ} \mathrm{PC} \mathrm{ACI}$ (arts. 14-16), la gestión democrática (2. ${ }^{\circ} \mathrm{PC} \mathrm{ACl}$ ) (arts. 58 y 59) y el de participación económica 
(3. ${ }^{\circ} \mathrm{PC} \mathrm{ACl}$ ), que se concreta en varios preceptos (art. 1.3 -carácter mutualista y participativo-, art. 65 - reserva legal-, art. 66 -retorno-, art. 67 —distribución de excedentes y remuneración limitada del capital social-, art. 75 - distribución del activo en caso de disolución). Sin embargo, si se entra en el detalle de todos estos artículos se encuentran excepciones y salvedades a la mayoría de estos principios, (voto plural, existencia de socios inversores, posibilidad de sistemas alternativos al reparto en caso de disolución, etc.) por lo que la obligación a su respeto queda muy limitada. En cambio, nada dice el RSCE, sobre el principio de autonomía e independencia (4. ${ }^{\circ} \mathrm{PC} \mathrm{ACl}$ ), el de educación, formación e información (5. ${ }^{\circ} \mathrm{PC} \mathrm{ACl}$ ), el de cooperación entre cooperativas $\left(6 .^{\circ} \mathrm{PC} \mathrm{ACl}\right)$ y el de interés por la comunidad (7. ${ }^{\circ} \mathrm{PC} \mathrm{ACI}$ ), lo que no significa que no se pueda regular estatutariamente para modelar una SCE como una verdadera cooperativa.

En cuanto al necesario carácter internacional de la SCE, que es un aspecto clave, el artículo 2 RSCE establece a la necesidad de que en su constitución concurran, como mínimo, cinco personas físicas de dos Estados miembros diferentes; cinco personas y sociedades de dos Estados miembros; sociedades de dos Estados miembros; la fusión de cooperativas de dos Estados miembros; o la transformación de una cooperativa con establecimiento o filial con más de dos años de antigüedad en otro Estado miembro de la UE. Es decir, los fundadores deben de proceder de, al menos, dos países de la Unión Europea diferentes. Esto, evidentemente, reduce el número de cooperativas que pueden constituirse como SCE, puesto que, aunque esto depende del tipo de cooperativa de que se trate, el desarrollo en común de la actividad cooperativizada suele exigir una proximidad física de los miembros de la sociedad. Por eso, lo normal es que la mayoría de las SCE, especialmente las conformadas por personas físicas, se desarrollen en zonas limítrofes o fronterizas entre varios Estados de la Unión Europea.

\section{El complejo sistema de fuentes del Estatuto de la Sociedad Cooperativa Europea}

Uno de las cuestiones más criticables del Estatuto de la SCE es el complejo sistema de fuentes que contiene el artículo 8.1 RSCE, y que trascribo como punto de partida al análisis de la cuestión: "LaS SCE se regirán: a) por lo dispuesto en el presente Reglamento; b) cuando el presente Reglamento lo autorice expresamente, por las disposiciones de los estatutos de la SCE; c) respecto de las materias no reguladas por el presente Reglamento o, si se trata de materias reguladas sólo 
en parte, respecto de los aspectos no cubiertos por el presente Reglamento: i) por la legislación que adopten los Estados miembros en aplicación de medidas comunitarias que se refieran específicamente a las SCE; ii) por las leyes de los Estados miembros que fuesen de aplicación a una sociedad cooperativa constituida con arreglo a la legislación del Estado miembro en el que la SCE tenga su domicilio social; iii) por las disposiciones de los estatutos, en las mismas condiciones que rigen para las sociedades cooperativas constituidas con arreglo a la legislación del estado miembro en el que la SCE tenga su domicilio social».

Es decir, la SCE se rige, en primer lugar, por lo dispuesto de manera imperativa por el RSCE y, de manera subsidiaria, por las disposiciones estatutarias si el Reglamento lo autoriza expresamente. Algunos ejemplos de aspectos regulados imperativamente por la SCE, es que el capital social mínimo se establece en $30.000 €$ (art. 3.2), que el $25 \%$ del capital social debe estar desembolsado (art. 4.4), que el domicilio social de la SCE debe situarse en el Estado miembro en que esté la administración central (art. 6) o que la administración de la SCE se puede organizar por un sistema monista (órgano de administración) o dualista (órgano de control y órgano de dirección).

De este modo, aunque la ley nacional de cooperativas de un Estado regule de distinta manera estos aspectos, la SCE cuyo domicilio esté en dicho Estado tiene que cumplir con el contenido del RSCE en estas materias. Lo que ocurre es que en determinados casos esta posible colisión normativa es de difícil interpretación. Por poner un ejemplo, el artículo 16.1 RSCE establece que «la pérdida de la condición de socio dará derecho al reembolso de la parte del capital suscrito, deducida, en su caso, la parte proporcional de las pérdidas imputables al capital social». ¿Significa esto entonces qué no se pueden establecer estatutariamente aportaciones no reembolsables?, cuando después de la promulgación de la NIC 32 esta posibilidad se ha normalizado en los ordenamiento de toda Europa para evitar que el capital social sea calificado como pasivo en lugar de recursos propios; ¿o significa que no se puede hacer deducciones al importe a reembolsar en caso de expulsión o baja no justificada, que son tan típicos del Derecho cooperativo?.

Por otra parte, en multitud de ocasiones el RSCE hace remisión expresa a la legislación nacional aplicable a las sociedades cooperativas [aproximadamente en quince ocasiones, por ejemplo, para prever la admisión de socios inversores (no usuarios) (art. 14.1, 2); el régimen de responsabilidad de los administradores (art. 51); la posibilidad del voto plural (art. 60.2), etc.] y a la legislación aplicable a las sociedades anónimas [también aproximadamente quince veces, por ejemplo en materia de inscripción (art. 11), publicidad legal (art. 12), proceso de fusión 
de cooperativas (art. 26), cuentas anuales (arts. 68 y s.), auditoría de cuentas (ars. 70 y s.), etc.]. Respecto a esto último, volvemos a insistir, que aunque la ley nacional de cooperativas regule estos aspectos de manera distinta, para las SCE cuyo domicilio social esté en dicho Estado miembro, debe regir la normativa aplicable a las sociedades anónimas. Un ejemplo: En España existen diecisiete leyes de cooperativas (dieciséis autonómicas y una estatal), un Registro de Cooperativas estatal y uno por CC.AA. Pues bien, dada la remisión a la normativa nacional sobre SA en materia registral, la inscripción de las SCE domiciliadas en España se debe hacer en el Registro Mercantil (y no en el Registro de Cooperativas) que corresponde a su domicilio social (art. 3 Ley 3/2011).

En un segundo nivel en la jerarquía de fuentes están, tal como establece en el artículo 8 RSCE, el contenido de los estatutos sociales pero sólo cuando el Reglamento lo autorice expresamente, algo que hace de manera profusa a lo largo de su texto. Sólo pondré dos ejemplos, de las más de cincuenta remisiones a los estatutos que he contabilizado: "La SCE no podrá admitir que terceros no socios se beneficien de sus actividades o participen en sus operaciones salvo disposición en contrario de los estatutos» (art. 1.4); "Los estatutos podrán prever que las distintas categorías de participaciones (en el capital social) confieran distintos derechos en lo que respecta a la distribución de resultados» (art. 4.1, 2). De este modo, aunque la ley nacional de cooperativas no prevea estos aspectos o los regulen de otra manera, los estatutos de la SCE lo pueden regular contra legem.

El tercer escalón de fuentes, que entra en juego en las materias total o parcialmente no reguladas en el RSCE (lo que requiere una compleja labor de indagación de qué aspectos están o no cubiertos por el Reglamento) está compuesto a su vez por tres niveles: la legislación específica sobre las SCE que adopten los Estados miembros; la disposiciones imperativas de las leyes nacionales aplicables a sus cooperativa; y por el contenido dispositivo de las mismas recogido en los estatutos sociales [que es la interpretación que hago del complejo contenido del apartado c) del art. 8 RSCE].

Lo que ocurre, es que en muchas ocasiones no se sabe con certeza si una cuestión está total o parcialmente regulada por el RSCE, por lo que se genera gran incertidumbre jurídica de si es o no de aplicación las ley nacional. Por ejemplo, parece claro, que como el RSCE no contiene un régimen de disciplina social será de aplicación las leyes nacionales de cooperativas y el posible el desarrollo estatutario que permiten éstas en esta materia. Pero, en operaciones con terceros, que el RSCE las permiten si lo prevén los estatutos de la SCE (art. 1.4) ¿deben limitarse como establecen muchas normas nacionales a un tanto por 
ciento del volumen de la operaciones con sus socios?. O por ejemplo, en materia de reservas legales, que el RSCE establece que se han de dotar como mínimo con el 15\% de los excedentes anuales (art. 65.2), ¿sería aplicable las normas nacionales que fijan un porcentaje para el Fondo de Educación y Promoción? y ¿sería de aplicación el trato de cooperativas fiscalmente protegidas cuando éste suele depender de la dotación de estos fondos o de que la cooperativa realice sus actividad principalmente con sus socios?. Por dar mi opinión, una SCE domiciliada en España que haga operaciones con terceros sin respetar los límites de la legislación española, que no dote el FEP y sólo dote el FRO con un 15\%, debería recibir el trato de cooperativa protegida de la Ley 20/1990 de Régimen Fiscal de las Cooperativas (art. 6) pero no el de especialmente protegida (arts. 7 y s.).

Por último, en relación a la legislación que podían y, en muchos casos, debían, adoptar los Estados miembros para desarrollar o aclarar determinadas cuestiones contenidas en el RSCE, algunos países europeos no han dado aún los pasos necesarios para hacer efectiva la aplicación del Reglamento, y los que han adoptado normas al respecto lo han hecho con mucho retraso, lo que ha limitado considerablemente la constitución de este tipo de entidades en Europa. En España, en particular, se promulgó la Ley 3/2011, de 4 de marzo, por la que se regula la Sociedad Cooperativa Europea con domicilio en España, cuyo contenido paso brevemente a describir.

El capítulo I recoge las disposiciones generales, aclarando la discutida cuestión de qué ley cooperativa es la aplicable en los aspectos no regulados por el RSCE, optando porque sea la del lugar donde realice principalmente la actividad cooperativizada, que es tanto como decir la ley de cooperativa de la autonomía correspondiente a dicho domicilio social. Considero que se ha perdido una oportunidad de homogeneizar algo el régimen de las cooperativas en España, puesto de haber optado por la Ley 27/1999 estatal de cooperativas como ley nacional aplicable de manera subsidiaria al RSCE, se evitaría, al menos para estas cooperativas, que se suponen tendrán gran tamaño, la fragmentación de la legislación cooperativa que existe en nuestro país.

El mismo capítulo I de la Ley 3/2011 determina que el Registro Mercantil como competente en materia de inscripción y publicación de actos de la SCE y establece las reglas de traslado de la SCE y oposición al mismo. El capítulo II contienen las peculiaridades específicas de la legislación cooperativa en relación con los actos de fusión y transformación de cooperativas en SCE. Por su parte, el capítulo III contempla el desarrollo del sistema dual que no es el propio de la legislación española y que era necesario regular para permitir este modelo de administra- 
ción de la SCE. Por último, el capítulo IV trata de los supuestos de disolución de la SCE, determinando que el Juez de lo Mercantil del domicilio social de la SCE es el órgano competente para declararla.

\section{Situación y perspectivas}

EI RSCE concede un amplio margen para configurar a las sociedades cooperativas europeas, con lo que podemos encontrarnos con SCE muy economicistas y poco respetuosas con los principios cooperativos al estilo germánico, o sociedades más mutualistas y con un sentido del cooperativismo más puro, como tradicionalmente se ha dado en los ordenamientos latinos. Pero para saber qué tipo de cooperativa es determinada SCE y cuál es su régimen jurídico, es absolutamente necesario conocer el concreto contenido de los estatutos sociales y del Derecho nacional del Estado donde se domicilie la entidad.

Un ejemplo puede ser ilustrativo de lo que digo. Pensemos en una sociedad danesa que va a hacer determinadas operaciones comerciales con una SCE española domiciliada en Almería (provincia líder de exportación de productos hortofrutícolas en todas Europa) y le interesa conocer el régimen de responsabilidad de los administradores sociales. Pues bien, los estatutos de la SCE estarán en español e inscritos en el Registro Mercantil de la ciudad de Almería y la legislación aplicable al régimen de responsabilidad de los administradores, por remisión del artículo 51 RSCE, será el contenido en el artículo 50 de la Ley 14/2011 de Sociedades Cooperativas Andaluzas. Esta indagación jurídica, aunque explicada en dos frases, puede tener en la práctica un elevado coste para la empresa danesa. Aunque también es cierto que parecida labor de investigación jurídica habría que realizar si se contrata con una cooperativa nacional, lo que es innegable es que no se ha logrado el objetivo de simplificación y homogeneización que se pretendía con la aprobación del RSCE.

Pero, de otro lado, es cierto que con un adecuado asesoramiento se puede configurar una SCE a medida de los intereses de los socios, y eludir así, si se quiere, muchas de las limitaciones existente en los derechos nacionales en cuanto a dotación de fondos, operaciones con terceros, reparto de los resultados positivos y muchísimos otros aspectos que pueden incomodar, en términos económicos y financieros, a las cooperativas.

En todo caso, la figura no ha funcionado, como demuestran los números. Hasta 2012 se habían constituido en Europa sólo 24 SCE, con un número de trabajadores inferior a cincuenta. El record en consti- 
tuir SCE lo tiene Eslovaquia con siete, aunque, como ocurre con la SE, con el desmerito de que la mayoría de sus SCE, por no decir todas, están inactivas y se han creado de manera profesional con la intención de transmitirla a terceros posteriormente. En segundo lugar, con cinco SCE, está Italia, donde se constituyó en julio de 2006 la primera SCE denominada ESCOOP, creada por un grupo de organizaciones italianas, finesas y españolas para operar en el ámbito de los servicios sociales y la administración pública. Tres se han constituido en Hungría, dos en Alemania y Bélgica, y sólo una en Francia, Holanda, Suiza y España (Euskal Herriko Ikastolak, que agrupa a varias escuelas de enseñanza en euskera del País Vasco español y francés). De este modo, en veintiún países de la UE no se ha constituido ninguna SCE, siendo además llamativo el escaso número de las creadas en países con un movimiento cooperativo tan activo, como son Francia, España o Alemania.

Consciente de esta realidad, y para dar adecuado cumplimiento al contenido del artículo 79 RSCE que establece cinco años después de su puesta en marcha, la Comisión debía presentar al Parlamento Europeo y al Consejo un informe sobre la aplicación del RSCE junto con propuestas de modificación de su contenido, se evaluaron en 2011 a través de una consulta pública los motivos de la escasa adhesión del cooperativismo europeo al estatuto de la SCE (cuyos resultados están disponibles en http://ec.europa.eu/enterprise/policies/sme/public-consultation/ past-consultations/index2_en.htm). Finalmente en febrero de 2012 se publicó el Informe de la Comisión sobre la aplicación del RSCE detallando las razones del fracaso de la figura.

El principal de ellos, sin duda, es la falta de incentivos para constituir SCE para los operadores económicos. A esto se le añade unos altos costes de constitución y la complejidad de proceso, con numerosas referencias a la legislación nacional, que genera gran incertidumbre sobre cuál es la norma aplicable en cada caso. Como hemos intentado demostrar estamos ante un tipo social complejo, con muchas remisiones y que genera dudas importantes sobre su régimen, que a su vez lleva a una falta de especialización de los asesores de cooperativas de las ventajas y posibilidades de la SCE frente a las cooperativas nacionales.

También se apunta en el Informe de la Comisión que las normas nacionales para desarrollar el RSCE y transponer la Directiva sobre la implicación de los trabajadores han sido implementadas muy tarde, lo que no ha favorecido al desarrollo de la figura. Además, hay un hecho que a veces se olvida: no hay suficiente número de cooperativas que les intereses constituir o convertirse en SCE, simplemente porque la internacionalización de su actividad se puede lograr de manera más sencilla a través de cooperativas nacionales $y$, porque la necesaria 
proximidad de los socios de las cooperativas para el desarrollo de la actividad mutualista, dificulta la concurrencia de socios de distintos países necesaria para constituir una SCE. La Propuesta a la Comisión Europea se cierra con la necesidad de revisar el RSCE para facilitar su utilización, proponiendo una simplificación de la norma, que la haga mas inteligible, con menos remisiones a la legislación nacional de cada país y, por tanto, más fácilmente aplicable. Esperemos que la anunciada revisión del Reglamento de la SCE logre conformar un Estatuto claro, sencillo y atractivo para las cooperativas europeas.

\section{Bibliografía}

AA.VV. La Sociedad Anónima Europea: régimen jurídico societario, laboral y fiscal (Dir. FERNÁNDEZ DEL POZO-ESTEBAN VELASCO), Madrid, Marcial Pons, 2004.

AA. VV. La Sociedad Cooperativa europea domiciliada en España (Dir. ALFONSO SÁNCHEZ), Cizur Menor, Aranzadi, 2008.

ALFONSO SÁNCHEZ, R. «Respuesta del Ordenamiento Jurídico español ante la Sociedad Cooperativa Europea», CIRIEC-Jurídica, núm. 21, 2010, pp. 169-198.

BENETTI, M. «La Società cooperativa europa: scopo mutualistico e modalità di costituzione», La Rivista della Cooperazione, núm. 2, 2004, pp. 7-21.

COMISIÓN EUROPEA: Comunicación de la Comisión al Parlamento Europeo, al Consejo, al Comité Económico y Social Europeo y al Comité de las Regiones, Acta del Mercado Único: Doce prioridades para estimular el crecimiento y reforzar la confianza "Juntos por un nuevo crecimiento» (SEC (2011) 467 final).

COMISIÓN EUROPEA. Report «The application of Council Regulation (EC) No $1435 / 2003$ on the Statute for a European Cooperative Society» (SCE) COM (2012) 72 final (23-2-2012).

COMISIÓN DE INDUSTRIA, INVESTIGACIÓN Y ENERGÍA DE LA UNIÓN EUROPEA. Informe sobre la contribución de las cooperativas a la salida de la crisis, junio de 2013 (2012/2321 (INI)).

$\mathrm{FICl}$, A. «The European Cooperative Society Regulation», en International Handbook of Cooperative Law, (Dir. Cracogna-Fici-Henry), Heidelberg, Ed. Springer, 2013.

FUENTES NAHARRO, M. «La función del órgano de control de una sociedad cooperativa europea domiciliada en España», REVESCO, núm. 97, 2009, pp. 58-89.

GADEA, E., SACRISTÁN, F. y VARGAS VASSEROT, C. Régimen jurídico de la Sociedad Cooperativa del siglo XXI, Madrid, Dykinson, 2009.

GRIMALDOS GARCÍA, M.I. y PARDO M. ${ }^{a}$ M. "La excesiva complejidad del sistema de fuentes de la Sociedad Cooperativa Europea: confusión entre normas aplicables y remisiones profusas», Sociedad y Utopía, núm. 40, 2012, pp. 218-257. 
LAMBEA RUEDA, A. "Marco jurídico de la Sociedad Cooperativa Europea domiciliada en España», CIRIEC-Jurídica, núm. 17, 2006, pp. 85-111; también en La Ley, núm. 6479, mayo 2006, pp. 1-23.

MARTíNEZ SEGOVIA, F. «Introducción. Directiva y Reglamento sobre la Sociedad Cooperativa Europea», RdS, núm. 21, 2003, pp. 347- 350.

MARTíNEZ SEGOVIA, F. «Primera aproximación al Estatuto de la Sociedad Cooperativas Europea», REVESCO, núm. 80, 2003, pp. 61-106.

PASTOR SEMPERE, C. «La sociedad cooperativa europea domiciliada en España», REVESCO, núm. 97, 2009, pp. 117-144.

PASTOR SEMPERE, C. «La Sociedad Cooperativa Europea: la compleja articulación de un nuevo tipo societario», en AA.VV., en La internazionalización de la Sociedad Cooperativa, Valencia, Tirant Lo Blanch, Valencia, 2008

VARGAS VASSEROT, C. "EI Derecho de sociedades comunitario y la jurisprudencia del TJCE en la interpretación de las Directivas de Sociedades», RdS, 2004, núm. 22, pp. 305-334.

VARGAS VASSEROT, C. «Integración y diferenciación cooperativa: de las secciones a los grupos de sociedades», BAIDC, núm. 44, 2010, pp. 159-176.

VICENT CHULIÁ, F. «La Sociedad Cooperativa Europea», CIRIEC-Jurídica, núm. 14, 2003, pp. 51-82.

VICENT CHULIÁ, F. «A sociedade cooperativa europea e a libertade de establecemento da cooperativa na Unión Europea», Cooperativismo e Economía Social, núm. 26, 2003-2004, pp. 61-108.

ZENNA, F.A. "La Sociedad Cooperativa Europea, una ocasión perdida para la armonización y creación de un Derecho Comunitario. Los problemas de implantación del Estatuto en España», Anales de Derecho, núm. 26, 2008, pp. 649-666. 